\title{
DISLEXIA: UM ESTUDO DE CASO COM POSSIBILIDADES DE INTERVENÇÃO PEDAGÓGICA
}

\section{DYSLEXIA: A CASE STUDY WITH POSSIBILITIES OF PEDAGOGICAL INTERVENTION}

\author{
Marco Antônio Franco do Amaral \\ Instituto Federal do Triângulo Mineiro, MG, Brasil E-mail: marcoamaral@iftm.edu.br
}

\section{Sabrina Moura}

Instituto Federal Goiano, GO, Brasil E-mail: sabrinamoura396@gmail.com.br

\section{Fernanda Mendonça}

Instituto Federal Goiano, GO, Brasil E-mail: fernandafm_mendonca@outlook.com

\section{Géssica Alves de Sousa}

Instituto Federal Goiano, GO, Brasil E-mail: gessicasousa.ped@gmail.com

DOI: https://doi.org/10.46550/amormundi.v2i1.19

Recebido em: 12.12.2020

Aceito em: 14.01.2021

\begin{abstract}
Resumo: A dislexia é uma dificuldade de aprendizagem muito presente no ambiente escolar e tema de recorrentes discussóes que pode ser diagnosticada tanto na infância quanto na vida adulta. O presente artigo é oriundo de uma pesquisa qualitativa e bibliográfica que se inicia com um estudo teórico descrevendo posteriormente um estudo de caso. Ele tem como objetivo entender e analisar possíveis estratégias para ajudar um aluno disléxico, demonstrando aos educadores diferentes métodos para compreender suas capacidades e necessidades, chegando assim a uma definição de dislexia, suas causas e quais sinais são demonstrados pelo educando que podem ajudar a diagnosticar o transtorno. Observando que a dislexia é um distúrbio de aprendizagem e não uma doença e se diagnosticada no início os resultados de possíveis intervençóes podem obter mais sucesso, ou seja, o indivíduo vai melhorar o processo de ensino e aprendizagem mais facilmente, concluímos que se faz necessário o apoio da família em conjunto com a escola que deve orientar seus profissionais a desenvolver metodologias de ensino que possibilitem maior desenvolvimento do aluno.
\end{abstract}

Palavras-chave: Dislexia. Transtorno. Intervençôes. Metodologias.

Abstract: Dyslexia is a learning difficulty very present in the school environment and the subject of recurring discussions that can be diagnosed both in childhood and in adulthood. The present article comes from a qualitative and bibliographic research that begins with a theoretical study describing a case study. It aims to understand and analyze possible strategies to help a dyslexic student, showing educators different methods to understand their abilities and needs, thus reaching a definition of dyslexia, its causes and what signs are shown by the student that can help diagnose the disorder. Observing that dyslexia is a learning disorder and not a 
disease and if diagnosed at the beginning, the results of possible interventions can be more successful, that is, the individual will improve the teaching and learning process more easily, we conclude that it is necessary to family support in conjunction with the school, which should guide its professionals to develop teaching methodologies that enable greater student development.

Keywords: Dyslexia. Disorder. Interventions. Methodologies.

\section{Introduçáo}

dislexia é um transtorno de aprendizagem com origem neurobiológica e possíveis

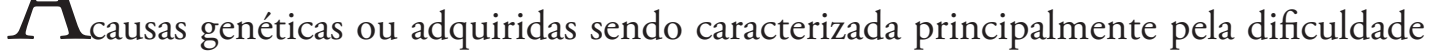
de leitura e escrita podendo prejudicar muito o desenvolvimento escolar da criança que necessita de estratégias educacionais e maior atenção do professor para seu desenvolvimento.

Muitas crianças podem ser afetadas por esse distúrbio que faz parte da realidade das salas de aula em diferentes fases do desenvolvimento cabendo a uma equipe de profissionais como pedagogo, fonoaudiólogo e psicólogo fazer seu diagnóstico com o intuito de facilitar o processo de alfabetização.

Desse modo, o presente estudo discute a seu respeito da dislexia apresentando um estudo de caso realizado em sala de aula com um aluno disléxico, tendo como objetivo um entendimento geral do transtorno, suas causas, sintomas e possíveis intervençóes. A dislexia faz parte do cotidiano de inúmeros pais e professores que por falta de conhecimento a respeito lidam de maneira incorreta com a situação que muitas vezes demora a ser diagnosticada dificultando o tratamento e as possibilidades de intervenção pedagógica.

\section{Metodologia}

Para Gil (2002), a pesquisa pode ser classificada com base nos seus objetivos e com ligação aos seus procedimentos técnicos. A metodologia desenvolvida nesta pesquisa fundamentase na pesquisa qualitativa, ou seja, tem base no caráter subjetivo, usando a literatura para o embasamento teórico e análise de um transtorno de aprendizagem denominado dislexia. Quanto aos objetivos esta pesquisa é entendida como exploratória e tem como objetivo

proporcionar maior familiaridade com o problema, com vistas a torná-lo mais explícito ou a constituir hipóteses. Pode-se dizer que estas pesquisas têm como objetivo principal o aprimoramento de idéias ou a descoberta de intuiçóes. Seu planejamento é, portanto, bastante flexível, de modo que possibilite a consideração dos mais variados aspectos relativos ao fato estudado. (GIL, 2002, p. 41).

Quanto aos procedimentos técnicos ela é classificada como um estudo de caso. Para Gil (2002) o estudo de caso é caracterizado por "uma modalidade de pesquisa amplamente utilizada nas ciências biomédicas e sociais. Consiste no estudo profundo e exaustivo de um ou poucos objetos, de maneira que permita seu amplo e detalhado conhecimento." Assim, estudo de caso qualitativo é uma exposição e verificação acentuada de um fato ou unidade social. Ele pode ser ainda qualificado como uma pesquisa empírica que analisa o fato em sua realidade e ocorre em um contexto restrito.

Com relação ao delineamento da pesquisa, foi realizada primeiramente uma seleção de 
autores observando suas consideraçóes e analisando como poderiam contribuir para o estudo desenvolvido que no presente momento está concluído. Posteriormente, foi feita uma verificação bibliográfica introdutória do assunto abordado no tema. A partir disto, foi construído e posteriormente analisado o estudo de caso.

pesquisa relata alguns resultados, como o processo de afetividade do aluno, família e professor é de grande importância para o desenvolvimento do disléxico; uso de metodologias diversificadas dentro do âmbito educacional é uma forma de estimular o discente para obter êxito; a participação da família tem grande relevância no processo de desenvolvimento de ensino e aprendizagem e o sistema de avaliação deve-se adequar as necessidades do aluno com transtorno.

\section{Desenvolvimento}

Atualmente, muito se discute a respeito da dislexia, assim abordaremos seus conceitos, sintomas e possíveis intervençôes necessárias para enfrentar seus obstáculos em atividades escolares, como leitura e escrita. Assim, diferentes autores conceituam a dislexia como

um transtorno genético e hereditário da linguagem, de origem neurobiológica, que se caracteriza pela dificuldade de decodificar o estímulo escrito ou o símbolo gráfico. A dislexia compromete a capacidade de aprender a ler e escrever com correção e fluência e de compreender um texto. Em diferentes graus, os portadores desse defeito congênito não conseguem estabelecer a memória fonêmica, isto é, associar os fonemas às letras. (BRUNA, 2011, p. 1).

Para (COSTA; MALLOY-DINIZ; MIRANDA, 2016, p.07) "a dislexia é caracterizada pela dificuldade com a fluência correta na leitura e por dificuldade na habilidade de traduçáo dos sons em letras e das letras em seus sons.” Ainda de acordo estes autores, crianças com dislexia geralmente demoram mais para começar a falar, têm mais dificuldade para pronunciar e aprender novas palavras, não entende rimas facilmente, e cometem mais erros ao escrever " $\mathrm{t}$ " por " $\mathrm{d}$ " ou "f" por "v".

Segundo Teles (2004, p. 03), “a dislexia é uma incapacidade específica de aprendizagem, de origem neurobiológica, é caracterizada por dificuldades na correção e/ou fluência na leitura de palavras e por baixa competência leitora e ortográfica”. Estas dificuldades resultam de um déficit fonológico, inesperado, em relação às outras capacidades cognitivas e às condiçóes educativas. Secundariamente podem surgir dificuldades de compreensão, experiência de leitura reduzida que pode impedir o desenvolvimento do vocabulário e dos conhecimentos gerais.

Desde então esta perturbação tem recebido diversas denominaçôes: "cegueira verbal congênita", "dislexia congênita", "estrefossimbolia", "alexia do desenvolvimento", "dislexia constitucional", "parte do contínuo das perturbaçóes de linguagem, caracterizada por um déficit no processamento verbal dos sons". (TELES, 2004, p.3).

De acordo com Rubino (2008, p.84), "a dislexia é um transtorno de aprendizagem hereditário e sem cura, que acarreta uma falha nas conexôes cerebrais, principalmente nas regióes responsáveis pela leitura, pela escrita e pela soletraçáo”. As dificuldades causadas por esse transtorno podem ser melhoradas em até $80 \%$ desde que seja diagnosticado o mais precocemente possível e tratado de forma adequada. 
Os disléxicos têm a inteligência acima da média, apesar de seu desempenho escolar sugerir ao contrário. As pessoas disléxicas mostram-se mais criativas e têm idéias inovadoras que superam as das não-disléxicas, uma vez que elas tendem a ativar outras áreas do cérebro para compensar as suas dificuldades. (RUBINO, 2008, p. 84-85).

A dislexia pode estar associada a outras perturbaçóes, pois

embora a base cognitiva da dislexia seja um déficit fonológico, é frequente a comorbilidade com outras perturbaçôes: perturbação da atenção com hiperatividade (ADHD), perturbação específica da linguagem (PEL), discalculia, perturbação da coordenação motora, perturbação do comportamento, perturbação do humor, perturbação de oposição e desvalorização da autoestima. (TELES, 2004, p.08).

\section{Dislexia: dificuldades correlacionadas}

O déficit fonológico, segundo Farrell (2008), é o bloqueio da pronúncia de uma criança e existe obstáculo em comparar sons da pronúncia a alteraçóes de sentido. Na dislexia, o principal déficit cognitivo está na eficácia de retratar ou recordar sons da fala (fonemas), ou seja, encontrase um obstáculo nas expressóes fonológicas. Essa carência fonológica leva ao mapeamento mental incompleto das letras do alfabeto em fonemas. Tanto o déficit fonológico, quanto o mapeamento grafema-fonema opera no nível cognitivo.

O reconhecimento e o parecer dos bloqueios fonológicos abarcam notar: revelação de incorreçóes, ausências ou outras dificuldades na modificação ou na interação em sala de aula no linguajar persuasivo da criança. No caso de a criança ter impedimento de adquirir a compreensão da fala, sugere que ela pode ter dificuldades nos elementos da fala que apresentam significados. Outra é a da dificuldade de percepçáo auditiva e de processamento auditivo, na qual menciona o autor que alguns aspectos sensórios da fala são pertinentes para o progresso da consciência fonêmica, foi proposto que a capacidade de leitura pode estar ligada à compreensão da fala, um aspecto da percepção auditiva refere-se à chamada categorização fonética. Na criação de diferentes sons da fala, há inúmeras duraçôes entre o instante da liberação do ar pelos lábios e a vibração das pregas vocais. Para notar as dificuldades de processamento auditivo, é preciso observar a presença de: dificuldades de discriminação, sequencialização, combinação e segmentação auditiva; inabilidade de percepção de sons consonantais em diferentes condições (inicial, medial, final).

Nas dificuldades visuais e processamento visual os alunos precisam de letras coloridas para se direcionar, pois as cores pretas e brancas fazem com que eles embaralhem as letras como elas estivessem flutuando. Também, se a escrita estiver bastante pequena irá causar uma dificuldade na criança, levando a perder o sentido das palavras e se distraem demorando a voltar no devido lugar onde pararam. Isso resulta na incapacidade de leitura. Uma teoria que está associada a esta dificuldade é a magnocelular na qual a criança tem dificuldades em produzir tarefas visuais, pois veem as letras embaralhas e desalinhadas.

Neste sentido, há observaçôes a serem feitas para avaliar as dificuldades visuais do aluno: indica uma dificuldade imprópria para a idade em distinguir letras que parecem as mesmas (m$\mathrm{n}$ ); apresenta uma complexidade indevida à idade para diferenciar letras que são as mesmas, mas tem formas alteradas (M-m); elimina ou transpóe parte de uma palavra (que pode indicar um problema de segmentação visual). 
As crianças que apresentam dislexia têm dificuldades motoras que podem refletir em sua ortografia e, assim, retardar as suas habilidades causando insucesso de algumas atividades desenvolvidas ao longo de sua vida escolar e pessoal. Enquanto as pessoas fazem atividades como manter o equilíbrio de modo automático, indivíduos disléxicos precisam dar uma atenção especial a isso. Para chegar a uma avaliação concreta dessa dificuldade, podem-se desenvolver atividades que envolvem a motricidade

Os indivíduos disléxicos podem ter consigo uma memória verbal de curto prazo, na qual tendem a memorizar palavras fáceis e curtas, desprezando frases longas e difíceis. Assim, devese utilizar uma linguagem direta, clara, objetiva e ainda verificar se o mesmo entendeu.

Para identificar que esse indivíduo tem as características acima se deve desenvolver atividades que abordam jogos de memória e observar se apresentam dificuldades em lembrar instruçôes, sequência de número, fatos e datas, compromissos e prazos de trabalhos.

$\mathrm{Na}$ dificuldade de sequencialização (ordem temporal), as pessoas apresentam uma resistência em dar sequência a certas atividades como: relatar a ordem de suas atividades ao longo do dia, sequência numérica.

\subsection{Fatores e indícios da dislexia}

Estudos recentes apontam como uma das causas da dislexia a produção excessiva de testosterona pela mãe durante a gestação da criança, origem neurobiológica e perturbaçóes no parto ou início da vida. A maioria dos casos a dislexia é descoberta a partir dos seis anos, pois é o momento que o aluno está sendo alfabetizado. Assim, delimitamos alguns fatores que podem causar a dislexia.

\subsubsection{Causas neurobiológicas}

Existe uma pequena alteração no cérebro que causa essa condição. Assim, o indivíduo possui algumas alteraçóes em partes do cérebro, porém utiliza partes do mesmo que outra pessoa sem dislexia não desenvolve ou tem dificuldade de acessar.

\subsubsection{Causas emotivas}

A dislexia também pode ocorrer por razóes emocionais, como por exemplo, no momento da descoberta do transtorno, pois esse indivíduo pode se sentir inferior em relação à sociedade. Por isso, o acompanhamento de familiares e equipe psicopedagógica é de extrema importância, pois quanto mais rápido ocorrer o procedimento de intervençóes melhor será para a saúde e desenvolvimento da pessoa.

\subsubsection{Causas associativas}

Um dos sinais que mais apontam para o diagnóstico de dislexia é o fato de haver uma maior demora do aluno em relacionar um conceito com uma palavra, um som com uma letra ou um texto. Portanto, o aluno com dislexia tem uma parte do cérebro atingida que bloqueia essa associação. 


\subsubsection{Causas metodológicas}

Os métodos utilizados para ensinar uma criança são fundamentais e devem ser aplicados observando-se as características de cada educando, pois um método mal aplicado ou sem estudo adequado para a produção do mesmo pode afetar gravemente um aluno e este desenvolver a dislexia.

Desta forma, precisa-se atentar a alguns sintomas: a) leitura tardia e lenta: é uma das formas mais claras, pois a criança não tem muito bem incorporada a associação entre letra e som, por isso vai ler de forma mais prolongada que o restante de seus amigos; b) não utiliza pontuaçôes e nem faz pausas: na leitura e na escrita, um disléxico não usa as pausas porque o seu sentido de espaço e de tempo é diferente. Além do que, também é comum que troque sílabas, palavras ou números de ordem; c) pouca habilidade física: além das questóes associadas com a leitura, uma pessoa disléxica também se reconhece porque fisicamente é desastrada, algo que se nota, principalmente na hora de praticar esporte e de realizar trabalhos manuais; d) náo distingue a direita da esquerda: também é um claro sintoma de que uma pessoa tem dislexia, pois a mesma tem dificuldades quanto à lateralidade.

\subsection{Estudo de caso}

Foi realizado um estudo de caso com um aluno do $6^{\circ}$ ano de uma escola de tempo integral. $\mathrm{O}$ educando de 11 anos diagnosticado com dislexia tem a presença de uma professora de apoio para ajudar a suprir suas necessidades. Esse educando apresenta uma leitura bastante lenta (silabada), nunca termina as tarefas passadas no quadro. O seu caderno é incompleto, cansa facilmente, tem receio de escrever textos ditados por um mediador, inseguro, disperso, tem uma memória curta e bastante agitado. Ele também exibe comportamento agressivo perante os colegas quando não consegue algo do seu interesse. Por isso, as avaliaçóes propostas a ele são adaptadas de acordo com a sua necessidade.

Sua família apresenta ser bastante presente em sua vida escolar e pessoal, deixando a escola intermediar o seu transtorno de aprendizagem. Porém, a escola não consegue dar apoio adequado para seu desenvolvido devido ao excesso de alunos com dificuldades para um único professor de apoio, sendo sete discentes para um docente.

Durante avaliação feita foi proposto um jogo de palavras chamado Aramumo: palavras cruzadas, desenvolvido em parceria entre o Instituto ABCD, Organização da Sociedade Civil de Interesse Público (OSCIP) que atua apoiando a educação de crianças com dificuldades e distúrbios de aprendizagens e Iniciativa de desenvolvimento de software dos alunos do Instituto Tecnológico de Aeronáutica (ITABITS). O objetivo do jogo é estimular a atenção, memorização e transformar fonemas em palavras concretas. $\mathrm{O}$ resultado foi bastante preciso em relação ao seu laudo de dislexia, uma vez que o aluno apontou dificuldades de memorizaçáo, espaço e tamanho das palavras. Enquanto ele demora 4 minutos para a realização do jogo, outro aluno da mesma idade e ano escolar sem dislexia realiza o mesmo jogo em poucos segundos. Outra avaliação proposta foi o ditado de um texto pequeno com sílabas similares e palavras curtas. $\mathrm{O}$ aluno mostrou-se bastante resistente no início e logo disse: "Eu não sei escrever com você ditando". O texto escrito pelo aluno apresentou palavras juntas e sem a percepção de separação, além das ausências de algumas letras. 


\section{Consideraçóes finais}

A dislexia é um distúrbio de aprendizagem e não uma doença, que possui tratamento, porém não tem cura e provoca dificuldades na leitura e escrita, se fazendo necessárias intervençôes como estratégias educacionais promovidas por um educador que deve adaptar as avaliações simplificando conteúdos para adequar as necessidades do aluno. $\mathrm{O}$ diagnóstico precoce é importante para o desenvolvimento do aluno, uma vez que intervenções adequadas com professores de apoio podem auxiliar em seu rendimento escolar. Desse modo, os docentes e a família necessitam saber reconhecer os sinais apresentados pela criança disléxica, pois, quanto antes o transtorno for descoberto mais favorável serão os métodos de intervenção.

É fundamental o apoio da família na vida escolar da criança estando presente no processo educacional proposto pela instituição dado que é na escola em que ficam mais claros os primeiros sinais da dislexia, sendo essencial também um suporte em casa havendo horários para fazer atividades além da afetividade que os pais devem transmitir à criança.

Não é necessário que a criança diagnosticada com dislexia fique em uma sala especial, pois tem muito a ofertar e a receber dos demais alunos. Contudo, para que tenha um bom desenvolvimento pedagógico os pais e professores podem tomar algumas atitudes. Os pais devem ter comunicaçáo com a escola e informar sobre as particularidades de seu filho como, por exemplo, suas potencialidades e capacidades. Eles devem também ajudar nas atividades de casa encontrando o melhor horário e preparando um lugar adequado que seja o mais silencioso possível com espaço suficiente para que se desenvolvam os exercícios.

A escola, por sua vez, deve trabalhar em colaboração com os responsáveis oferecendo informaçôes, disponibilizando um professor de apoio quando possível e orientando seus profissionais que precisam criar estratégias para interagir com o aluno disléxico em sala, usando sempre uma linguagem direta, clara e objetiva na hora das explicaçóes, verificando sempre seu entendimento; reconhecendo seus acertos e nas séries iniciais permitindo o uso de tabuadas, material dourado, ábaco; entre outras coisas.

Muitos professores possuem receio em trabalhar com crianças disléxicas, porém ao estar frente a esta situaçáo devem tratar o aluno com naturalidade, trazê-lo para perto da lousa, uma vez que isso favorece o diálogo facilitando o acompanhamento e a orientação, possibilitando o olhar direto no momento da fala. Como esse aluno possui suas particularidades, deve-se evitar submetê-lo a pressōes de tempo ou competiçóes com os colegas como, por exemplo, um pedido para que leia em voz alta.

Como o disléxico tende a responder melhor trabalhando com as partes do que com o todo, o professor ao apresentar o conhecimento fragmentado pode ser uma estratégia interessante para obter maior êxito, uma vez que estimular, incentivar e fazer com que o aluno se sinta capaz construindo sua autoestima também influencia no processo de aprendizagem.

Com relação ao processo avaliativo, como o aluno com dislexia tem dificuldade em entender o que lê, não deve ser aplicado avaliaçóes que contenham somente textos, principalmente científicos e longos. Antes de começar a prova o professor precisa ler em voz alta verificando se os alunos entenderam as perguntas e sempre que possível dar preferência às avaliaçóes orais por meio das quais o discente terá oportunidades de expor o que sabe sobre o assunto como se fosse uma conversa. 


\section{Referências}

BRUNA, Maria Helena Varella. Doenças e Sintomas: Dislexia. 2011. Disponível em:

$<$ https://drauziovarella.uol.com.br/doencas-e-sintomas/dislexia/>. Acesso em: 16 mar. 2018.

COSTA, Danielle de Souza; MALLOY-DINIZ, Leandro Fernandes; MIRANDA, Débora Marques de. Aprendizagem de A a Z: Cartilha de Aprendizagem. Belo Horizonte: Pearson, 2016. $26 \mathrm{p}$.

FARRELL, Michael. Dislexia e outras dificuldades de aprendizagem específicas: Guia do professor. Porto Alegre: Artmed, 2008. Tradução de: Maria Adriana Veríssimo Veronese.

GIL, Antonio Carlos. Como Elaborar Projetos de Pesquisa. 4. ed. São Paulo: Atlas, 2002

RUBINO, Rejane. Sobre o conceito de dislexia e seus efeitos no discurso social. Revistas Usp, São Paulo, v. 13, n. 24, p.84-97, jun. 2008.

TELES, Paula. Dislexia: Como identificar? Como intervir?.Revista Portuguesa de Clínica Geral, Lisboa, v. 20, n. 5, p.1-23, dez. 2004. 